\title{
INTERFERENCES OF HbA1c ANALYSIS IN HOSPITAL UNIVERSITI SAINS MALAYSIA - 3 YEARS STUDY
}

\author{
NOORAZLIYANA SHAFII ${ }^{1,4 *}$, NOOR AZLIN AZRAINI CHE SOH ${ }^{1,4}$, TUAN SALWANI TUAN ISMAIL ${ }^{1,4}$, \\ JULIA OMAR ${ }^{1,4}$, WAN NORLINA WAN AZMAN ${ }^{1,4}$, ANIZA MAT JELANI ${ }^{1,4}$, \\ WAN NOR FAZILA HAFIZAN WAN NIK ${ }^{1,4}$, IBRAHIM ISMAIL ${ }^{1,4}$, NUR KARYATEE KASSIM ${ }^{2,4}$, \\ HANIM AFZAN IBRAHIM ${ }^{2,4}$ and NAJIB MAJDI YAACOB ${ }^{3,4}$ \\ ${ }^{1}$ Department of Chemical Pathology, School of Medical Sciences, Universiti Sains Malaysia, \\ Health Campus, 16150 Kubang Kerian, Kelantan, Malaysia \\ ${ }^{4}$ Hospital Universiti Sains Malaysia, 16150 Kubang Kerian, Kelantan, Malaysia \\ ${ }^{2}$ School of Dental Sciences, Universiti Sains Malaysia, Health Campus, \\ 16150 Kubang Kerian, Kelantan, Malaysia \\ ${ }^{3}$ Unit of Biostatistics and Research Methodology, School of Medical Sciences, \\ Universiti Sains Malaysia, Health Campus, 16150 Kubang Kerian, Kelantan, Malaysia \\ *E-mail: noorazliyana@usm.my
}

Accepted 10 October 2021, Published online 30 November 2021

\begin{abstract}
Haemoglobin A1c $(\mathrm{HbA1c})$ is used to monitor glycaemic control and predict diabetic complications. Measurement of HbA1c can be interfered by haemoglobin $(\mathrm{Hb})$ variant and other $\mathrm{Hb}$ derivatives include carbamylated $\mathrm{Hb}$ and elevated labile A1 c. This study is to determine the percentages and type of interferences during $\mathrm{HbAlc}$ analysis and the percentages of nonreportable HbA1c results. This is a cross-sectional study using retrospective data of HbA1c. The HbA1c is measured on Biorad D10 using the ion-exchange high-performance liquid chromatography method. The data were analyzed using descriptive statistics. A total of 26,560 patients were included. The result showed the presence of interferences of $2269(8.56 \%)$. The most common causes of the interferences were the $\mathrm{Hb}$ variant $(8.48 \%)$ followed by carbamylated $\mathrm{Hb}$ and labile $\mathrm{A} 1 \mathrm{c}(0.03 \%$ each). The non-reportable $\mathrm{HbA} 1 \mathrm{c}$ results were $0.46 \%$ with the $\mathrm{Hb}$ variant contributed most of the causes. By knowing the presence of interferences particularly the $\mathrm{Hb}$ variant, the $\mathrm{HbAlc}$ results hopefully are interpreted with caution and correct management can be given to the patients.
\end{abstract}

Key words: Carbamylated haemoglobin, haemoglobin variants, HbA1c, HPLC, interferences, labile A1c

\section{INTRODUCTION}

Haemoglobin A1c (HbA1c) is glycated haemoglobin with glucose attached to the $\mathrm{N}$-terminal valine of the haemoglobin $(\mathrm{Hb}) \beta$-chain (Burtis et al., 2012). It reflects the plasma glucose concentration of the normal erythrocytes life span of 120 days (Lippi \& Targher, 2010). It is used to diagnose diabetes mellitus (DM), monitor glycaemic control, and predict diabetic complications. HbAlc can be quantified by various methods such as ion-exchange chromatography, affinity chromatography, enzymatic, and immunoassays.

Various factors may affect the accuracy of $\mathrm{HbA1c}$ results. These factors may interfere with

* To whom correspondence should be addressed.
HbA1c measurement during the analytical phase or the interpretation of the $\mathrm{HbA} 1 \mathrm{c}$ result. Analytical factors that need to be taken into consideration include the presence of $\mathrm{Hb}$ variants such as $\mathrm{HbS}$ or $\mathrm{HbC}$ trait, high fetal haemoglobin ( $\mathrm{HbF})$, chemically modified derivatives of $\mathrm{Hb}$ for example carbamylated $\mathrm{Hb}(\mathrm{carbHb})$ and elevated labile A1c (LA1c). These factors are highly method dependent and assay selection should be based on characteristics of samples (Nitin, 2010; Hare et al., 2012). In addition, factors affecting the glycation process also may impart a difficulty in $\mathrm{HbA} 1 \mathrm{c}$ interpretation. Any condition that shortens or prolonged erythrocytes life span such as iron deficiency anaemia, haemolytic anaemia, or acute blood loss will cause falsely low or high HbA1c levels (Gillery et al., 2000; Sacks et al., 2011). 
$\mathrm{Hb}$ variants result from amino acid changes that arise from mutations and/or deletions in the genes that encode $\alpha$ and $\beta$ chains. Hundreds of $\mathrm{Hb}$ variants have been identified, the most common are $\mathrm{HbS}, \mathrm{HbE}$, $\mathrm{HbC}$, and $\mathrm{HbD}$ (Rhea \& Molinaro, 2014). Individuals with homozygous $\mathrm{Hb}$ variants usually have reduced erythrocytes lifespan. Therefore, HbAlc is not recommended as a measure of glycaemic control in these patients. However, those with heterozygous diseases, such as $\mathrm{HbS}, \mathrm{HbC}, \mathrm{HbE}$ traits, and silent $\mathrm{Hb}$ variants, can potentially affect the accuracy of HbA1c measurement, in which the effect is methoddependent (Sacks et al., 2001). HbF is predominantly high at birth (between $60 \& 95 \%$ ) and reduces near to adult levels during the first year of life. High $\mathrm{HbF}$ levels can be found in hereditary persistence of $\mathrm{HbF}$ or certain conditions such as leukaemia, thalassemia, and anaemia (Little \& Roberts, 2009). CarbHb is found in a patient with renal failure and uraemia. $\mathrm{CarbHb}$ is formed by non-enzymatic condensation of cyanate with the N-terminal valine of $\mathrm{Hb}$ after dissociation of urea in vivo (Little et al., 2013). LA1c or pre$\mathrm{HbA1c}$ is an unstable Schiff base formed during nonenzymatic glycation of $\mathrm{Hb}$. Although ion-exchange high-performance liquid chromatography (HPLC) can separate the LA1c fraction, an abnormally high level of LA1c may produce error in the HbA1c measurement (Desmons et al., 2017).

Currently, ion-exchange HPLC is the most widely used method for HbA1c measurement. It separates $\mathrm{Hb}$ species based on the charges of the molecule (Rhea \& Molinaro, 2014). Ion-exchange HPLC is vulnerable to the effect of $\mathrm{Hb}$ variants (Chu et al. 2007; Chen et al., 2013). Inaccurate HbA1c results occurred if $\mathrm{Hb}$ variant or a derivative could not be separated from $\mathrm{HbA}$ or A1c peak (Gallagher et al., 2009). Falsely high or low HbA1c value caused by the presence of a silent $\mathrm{Hb}$ variant may lead to over or under-treatment of diabetic patients (Nasir et al., 2010). Although haemoglobinopathy can be detected through inspection of the chromatogram, the interferences of $\mathrm{Hb}$ variant and carbHb are variable in ion-exchange assays (Gallagher et al., 2009).

The identification of interferences, especially $\mathrm{Hb}$ variants is important for the accuracy of measurement. Therefore, this study is to determine the total and type of interferences during $\mathrm{HbA} 1 \mathrm{c}$ analysis.

\section{MATERIALS AND METHODS}

This is a cross-sectional study using retrospective data of patients' undergone HbAlc measurement in Endocrinology Laboratory, Hospital USM from January 2017 to December 2019. The HbA1c results and the demographic data were retrieved from the Laboratory Information System (LIS). Only one HbA1c result of the same patients was collected for the analysis. Repeated $\mathrm{HbA} 1 \mathrm{c}$ results were excluded from this study. The results were analyzed for reportable $\mathrm{HbA1c}$, presence of interferences, and non-reportable $\mathrm{HbA} 1 \mathrm{c}$. HbA1c is measured on Biorad D10 using the ion-exchange HPLC method. The variant is identified through inspection of the chromatogram during reporting the HbAlc by the presence of abnormal or unknown peaks before or after the A0 peak and the variant window peak after A0 (S-window or C-window). The HbA1c result will not be reportable if there is no HbA1c peak detected, combine areas of variant, $\mathrm{S}$ and $\mathrm{C}$ windows $\geq 60 \%$ (suspected having homozygous variant), $\mathrm{HbF} \geq 10 \%$, labile $\mathrm{HbA} 1 \mathrm{c} \geq 4 \%$, or the $\mathrm{HbA} 1 \mathrm{c}$ value is outside the linearity range $(3.8 \%$ to $18.5 \%)$. Hb analysis was not done for the suspected cases of the Hb variant.

Data analysis was performed using IBM SPSS Software version 26.0. Categorical variables were reported as frequency and percentage while numerical variables were described as mean and standard deviation (SD). The data are normally distributed (checked using a test of normality (Kolmogorov-Smirnov) and histogram with an overlaid normal curve). The percentage of the $\mathrm{Hb}$ variant was determined by adding the percentage of $\mathrm{Hb}$ variant with the percentage of $\mathrm{HbF}$ divided by the total number of $\mathrm{HbA} 1 \mathrm{c}$ requests.

$\begin{aligned} & \text { Percentage }(\%) \\ & \text { of } \mathrm{Hb} \text { variant }\end{aligned}=\frac{\% \text { of } \mathrm{Hb} \text { variant }+\% \text { of } \mathrm{HbF}}{\text { Total number of } \mathrm{HbAlc}}$ Equation 1

\section{RESULTS}

Total HbA1c requested from January 2017 to December 2019 was 57,623 . A total of 26,560 of the results were included after excluding repeated results from the same patients. The demographic characteristics were shown in Table 1. Males' participants $(50.7 \%)$ were more than females $(49.3 \%)$. The majority of the patients were Malay (94.6\%). A total of $2269(8.56 \%)$ of the HbA1c results were

Table 1. Baseline characteristic of patients $(n=26560)$

\begin{tabular}{lcc}
\hline Variables & Mean (SD) & $n(\%)$ \\
\hline Age (years) & $59.2(13.8)$ & \\
Sex & & \\
$\quad$ Male & $13,453(50.7)$ \\
Female & $13,107(49.3)$ \\
Race & \\
Malay & $25,135(94.6)$ \\
Chinese & $1,274(4.80)$ \\
Indian & $145(0.55)$ \\
Others & $6(0.02)$ \\
\hline
\end{tabular}


Table 2. The percentages and type of interferences of HbA1c results

\begin{tabular}{lc}
\hline Type & Frequency $(\%)$ \\
\hline Reportable with no interference & $24,279(91.41)$ \\
Interferences & $2,269(8.56)$ \\
Hb variant & $2,251(8.48)$ \\
Carbamylated Hb & $9(0.03)$ \\
Labile A1c & $9(0.03)$ \\
Rejected & $12(0.05)$ \\
\hline
\end{tabular}

Table 3. Causes of non-reportable $\mathrm{HbA} 1 \mathrm{c}$ results

\begin{tabular}{lc}
\hline Causes & Frequency $(\%)$ \\
\hline Hb variant & $100(0.38)$ \\
Carbamylated $\mathrm{Hb}$ & $9(0.03)$ \\
Labile $\mathrm{Hb}$ & $9(0.03)$ \\
Out of reportable range $(<3.8 \% \&>18.5 \%)$ & $6(0.02)$ \\
\hline
\end{tabular}

associated with interferences of which 2251 (8.48\%) were due to the $\mathrm{Hb}$ variant. Others were due to the presence of carbHb and LA1c $(0.03 \%$ each $)$. The rejected samples, due to clotted and wrong container contributed to $0.05 \%$. A total of $0.46 \%$ of the $\mathrm{HbA} 1 \mathrm{c}$ results were non-reportable with most of the cases were due to the $\mathrm{Hb}$ variant. Among the nonreportable $\mathrm{HbA} 1 \mathrm{c}$ results, the $\mathrm{Hb}$ variant contributed $4.44 \%$ of the causes. In these Hb variants, 39 (1.73\%) samples showed no peak during HbA1c analysis, and $31(1.38 \%)$ were $\mathrm{HbF}$. Other causes such as carbHb, LA1c, and $\mathrm{HbA} 1 \mathrm{c}$ results of $<3.8$ or $>18.5 \%$ respectively, contributed a small percentage to the non-reportable $\mathrm{HbA1c}$ results.

\section{DISCUSSION}

Over 20 years, the prevalence of DM among Malaysians aged more than 30 years old has increased more than two-fold. Currently, based on a multi-ethnic population, an HbA1c cut-off level of $6.3 \%$ is used for the diagnosis of DM (Wan Nazaimoon et al., 2013). The recommended HbA1c level in diabetic patients to prevent complications is $<6.5 \%$. Small changes in HbA1c measurement cause large changes in $\mathrm{HbA} 1 \mathrm{c}$ value since $\mathrm{HbA} 1 \mathrm{c}$ is expressed in the percentage of total $\mathrm{Hb}$ (Sabariah et al., 2013). Deviation of $1 \%$ of $\mathrm{HbA} 1 \mathrm{c}$ reflects a change of 1.4 to $1.9 \mathrm{mmol} / \mathrm{L}$ in average blood glucose concentration (Nasir et al., 2010).

This study revealed that the presence of interferences of $8.56 \%$ and non-reportable HbA1c results of $0.46 \%$. Hb variant was the most common cause of both results. $\mathrm{HbF}$ and $\mathrm{HbA} 1 \mathrm{c}$ with no peak were considered as $\mathrm{Hb}$ variants. Certain $\mathrm{Hb}$ variant especially homozygous has no HbA1c peak $(0 \%)$ because the analyzer could not measure the peak as the chromatograms showed a double peak (Camargo \& Gross, 2004). A study has reported that the percentage of $\mathrm{Hb}$ variants of $2.3 \%$ and $2.2 \%$ from these $\mathrm{Hb}$ variants were non-reportable (Sabariah et al., 2013). In contrast, our study showed higher percentages of $\mathrm{Hb}$ variants $(8.48 \%)$. This is probably due to the high prevalence of $\mathrm{HbE}$ with $\alpha$ thalassemia as a result of mixed marriage and migration of Thai population since Kelantan is bordering to Thailand (Thevarajah et al., 2009). The prevalence of thalassemia and haemoglobinopathies are high in Thailand and $\mathrm{HbE}$ is the most common structural $\mathrm{Hb}$ variant (Nitin, 2010).

$\mathrm{Hb}$ variant can cause interference on $\mathrm{HbA} 1 \mathrm{c}$ measurement in many ways. The HbAlc results would be falsely low regardless of the methods used if the variant causes reduced erythrocytes life span. $\mathrm{Hb}$ variants $\mathrm{S}, \mathrm{C}, \mathrm{D}$, and $\mathrm{E}$ which cause changes in the net charge of $\mathrm{Hb}$ interfere with ion-exchange HPLC or electrophoresis method and some $\mathrm{Hb}$ variants may co-elute or co-migrate with $\mathrm{HbA} 1 \mathrm{c}$ (Little \& Sacks, 2009). The HbA1c results become inaccurate when $\mathrm{Hb}$ variants or glycated derivate cannot be separated from HbA or HbA1c (Bry et al., 2001; Lorenzo-Medina et al., 2014). When compared to heterozygous which are silent variants, $\mathrm{HbA} 1 \mathrm{c}$ is inappropriate for the assessment of glycaemic control in patients with homozygous $\mathrm{Hb}$ variant such as $\mathrm{HbS}, \mathrm{HbC}, \mathrm{HbSC}$ diseases, or any other conditions with altered erythrocytes survival (Zhang et al., 2018). The method of choice is using serum fructosamine as it is not affected by the $\mathrm{Hb}$ variant. Serum fructosamine depends on the glycation of protein and reflects shorter glycaemic status which is 1 to 2 weeks (Schnedl et al., 2001). The presence of $\mathrm{Hb}$ variant is suspected and should be assessed if the patient's home blood glucose monitoring level and $\mathrm{HbAlc}$ results were not consistent (LorenzoMedina et al., 2014).

Furthermore, this study found only $0.03 \%$ of the interferences were from carbHb or LA1c. A study by Desmons et al. (2017) showed a significant interference when LA1c exceeded $4 \%$ and carbHb exceeded $2 \%$. This interference may affect the $\mathrm{HbA} 1 \mathrm{c}$ level and patient management (Desmons et al., 2017). For the HPLC method, the error from carbHb and LA1c can be minimized by proper inspection of the chromatogram. Hence, the interference from carbHb and LA1c is minimized. Most of the methods especially ion-exchange HPLC can detect carbHb levels, which accurately measures the HbA1c in renal failure patients and LA1c was observed as a distinct peak on the chromatogram (Little et al., 2013; Sivaraman \& Patel, 2015). 


\section{CONCLUSION}

The presence of interferences such as $\mathrm{Hb}$ variant during $\mathrm{HbAlc}$ interpretation should be avoided to prevent mismanagement of the diabetic patients. Further testing by other methods needs to be performed and $\mathrm{Hb}$ variant identification is important for the proper management of patients.

\section{ACKNOWLEDGEMENTS}

We would like to thank Hospital USM for the facilities. This study received no external funding.

\section{REFERENCES}

Bry, L., Chen, P.C. \& Sacks, D.B. 2001. Effects of haemoglobin variants and chemically modified derivatives on assays for glycohaemoglobin. Clinical Chemistry, 47(2): 153-163.

Burtis, C.A., Ashwood, E.R. \& Bruns, D.E. 2012. Tietz textbook of Clinical Chemistry And Molecular Diagnostics-e-book. Elsevier Health Sciences, US. 879 pp.

Camargo, J. \& Gross, J. 2004. Conditions associated with very low values of glycohaemoglobin measured by an HPLC method. Journal of Clinical Pathology, 57(4): 346-349.

Chen, C.F., Chien, C.M., Liu, S.C. \& Tai, Y.K. 2013. A rare haemoglobin variant (Hb Iraq-Halabja) causing spuriously low haemoglobin A1c values. Internal Medicine, 52(21): 2443-2446.

Chu, C.H., Wang, M.C., Sun, T.H., Lee, J.K. \& Lam, H.C. 2007. Very low HbA1c values in a patient with clinical silent haemoglobin variant (Haemoglobin J): A case report. Journal of Internal Medicine of Taiwan, 18: 45-50.

Desmons, A., Jaisson, S., Leroy, N., Gillery, P. \& Guillard, E. 2017. Labile glycated haemoglobin and carbamylated haemoglobin are still critical points for HbA1c measurement. Biochemia medica: Biochemia Medica, 27(2): 378-386.

Gallagher, E.J., Le Roith, D. \& Bloomgarden, Z. 2009. Review of haemoglobin A1c in the management of diabetes. Journal of Diabetes, 1(1): 9-17.

Gillery, P., Hue, G., Bordas-Fonfrede, M., Chapelle, J.P., Drouin, P., Levy-Marchal, C., Thivolet, C., Vialettes, B., Slama, G., Selam, J.L. \& Perier, C. 2000. Haemoglobin A1c assays and haemoglobinopathies: Problems and strategies. Annales de Biologie Clinique, 58(4):425-9
Hare, M.J., Shaw, J.E. \& Zimmet, P.Z. 2012. Current controversies in the use of haemoglobin A1c. Journal of Internal Medicine, 271(3): 227-236.

Lippi, G. \& Targher, G. 2010. Glycated haemoglobin (HbA1c): Old dogmas, a new perspective? Clinical Chemistry And Laboratory Medicine, 48(5): 609-614.

Little, R.R. \& Roberts, W.L. 2009. A review of variant haemoglobins interfering with haemoglobin A1c measurement. Journal of Diabetes Science and Technology, 3(3): 446-51.

Little, R.R., Rohlfing, C.L., Tennill, A.L., Hanson, S.E., Connolly, S., Higgins, T., Wiedmeyer, C.E, Weykamp, C.W., Krause, R. \& Roberts, W. 2013. Measurement of HbA1c in patients with chronic renal failure. Clinica Chimica Acta, 418: 73-76.

Little, R.R. \& Sacks, D.B. 2009. HbA1c: How do we measure it and what does it mean? Current Opinion in Endocrinology, Diabetes and Obesity, 16(2): 113-118.

Lorenzo-Medina, M., De-La-Iglesia, S., Ropero, P., Nogueira-Salgueiro, P. \& Santana-Benitez, J. 2014. Effects of haemoglobin variants on haemoglobin a1c values measured using a high-performance liquid chromatography method. Journal of Diabetes Science and Technology, 8(6): 11681176.

Nasir, N.M., Thevarajah, M. \& Yean, C.Y. 2010. Haemoglobin variants detected by haemoglobin A1c (HbA1c) analysis and the effects on HbA1c measurements. International Journal of Diabetes in Developing Countries, 30(2): 86.

Nitin, S. 2010. HbA1c and factors other than diabetes mellitus affecting it. Singapore Medical Journal, 51(8): 616-622.

Rhea, J.M. \& Molinaro, R. 2014. Pathology consultation on $\mathrm{HbA} 1 \mathrm{c}$ methods and interferences. American Journal of Clinical Patho$\log y$, 141(1): 5-16.

Sabariah, M., Lim, C., Chen, D., Choy, S. \& Nor'ashikin, O. 2013. Percentage of haemoglobin variants detected during HbA1c Analysis in Hospital Kuala Lumpur. Malaysian Journal of Medicine and Health Sciences, 9(2): 13-17.

Sacks, D., Bry, L. \& Chen, P. 2001. Effects of Hb variant and chemically modified derivatives on assays for glycohaemoglobin. Clinical Chemistry, 47(2): 153-163.

Sacks, D.B., Arnold, M., Bakris, G.L., Bruns, D.E., Horvath, A.R., Kirkman, M.S., Lernmark, A., Metzger, B.E. \& Nathan, D.M. 2011. Guidelines and recommendations for laboratory analysis in the diagnosis and management of diabetes mellitus. Clinical Chemistry, 57(6): e1-e47. 
Schnedl, W.J., Liebminger, A., Roller, R.E., Lipp, R.W. \& Krejs, G.J. 2001. Haemoglobin variants and determination of glycated haemoglobin (HbA1c). Diabetes/Metabolism Research and Reviews, 17(2): 94-98.

Sivaraman, P., Patel, N. 2015. HPLC: Its continuing role in diabetes monitoring. Medical Laboratory Observer, 47(6): 8-12.

Thevarajah, M., Nadzimah, M. \& Chew, Y. 2009. Interference of haemoglobinA1c (HbA1c) detection using ion-exchange high performance liquid chromatography (HPLC) method by clinically silent haemoglobin variant in University Malaya Medical Centre (UMMC) - A case report. Clinical Biochemistry, 42(4-5): 430-434.
Wan Nazaimoon, W.M., Md Isa, S.H., Wan Mohamad, W.B., Khir, A.S., Kamaruddin, N.A., Kamarul, I.M., Mustafa, N., Ismail, I.S., Ali, O. \& Khalid, B.A.K. 2013. Prevalence of diabetes in Malaysia and usefulness of $\mathrm{HbAlc}$ as a diagnostic criterion. Diabetic Medicine, 30(7): 825-828.

Zhang, X.M., Wen, D.M., Xu, S.N., Suo, M.H. \& Chen, Y.Q. 2018. Effects of haemoglobin variants HbJ Bangkok, HbE, HbG Taipei, and $\mathrm{HbH}$ on analysis of glycated haemoglobin via ion exchange high performance liquid chromatography. Journal of Clinical Laboratory Analysis, 32(1): e22214. 
